\title{
Energy Distributions in a Diesel Engine Using Low Heat Rejection (LHR) Concepts
}

\author{
Tingting Li \\ Department of Mechanical Engineering, Texas A\&M University \\ College Station, Texas 77843-3123, United States \\ tingting.li@tamu.edu \\ Jerald A. Caton \\ Department of Mechanical Engineering, Texas A\&M University \\ College Station, Texas 77843-3123, United States \\ jcaton@tamu.edu

\section{Timothy J. Jacobs*} \\ Department of Mechanical Engineering, Texas A\&M University, \\ College Station, Texas 77843-3123, United States \\ tijacobs@tamu.edu

\section{*Corresponding Author: Timothy J. Jacobs \\ Email: tjjacobs@tamu.edu}

\begin{abstract}
The energy balance analysis is recognized as a useful method for aiding the characterization of the performance and efficiency of internal combustion (IC) engines. Approximately one-third of the total fuel energy is converted to useful work in a conventional IC engine, whereas the major part of the energy input is rejected to the exhaust gas and the cooling system. The idea of a low heat rejection (LHR) engine (also called "adiabatic engine") was extensively developed in the 1980s due to its potential in improving engine thermal efficiency via reducing the heat losses. In this study, the LHR operating condition is implemented by increasing the engine coolant temperature (ECT). Experimentally, the engine is overcooled to low ECTs and then increased to $100^{\circ} \mathrm{C}$ in an effort to get trend-wise behavior without exceeding safe ECTs. The study then uses an engine simulation of the conventional multi-cylinder, four-stroke, 1.9L diesel engine operating at $1500 \mathrm{rpm}$ to examine the five cases having different ECTs. A comparison between experimental and simulation results show the effects of ECT on fuel conversion efficiency. The results demonstrate that increasing ECT yields slight improvements in net indicated fuel conversion efficiency, with larger improvements observed in brake fuel conversion efficiency.
\end{abstract}

Keywords: Low Heat Rejection; Engine Coolant Temperature; Energy Balance; Fuel Conversion Efficiency 


\section{Introduction}

38 Energy efficiency is one of the most significant assessment factors concerned with the internal

39 combustion engine. From the perspective of thermodynamics, the IC engine may theoretically

40 approach $100 \%$ efficiency since the IC engine converts chemical energy to mechanical energy;

41 chemical energy is fully available to do useful work. The IC engine will still be limited,

42 however, by second law considerations such as irreversible processes [1-2]. Actual IC engines

43 generally convert only approximately one-third of the fuel energy to useful work; the rest is

44 rejected typically in the form of thermal energy to the coolant and exhaust.

The LHR concept has been of interest since the 1980s, when a substantial number of programs

47 investigated the "adiabatic engine" [3-5]. These programs aimed to improve engine efficiency

48 with partial/complete suppression of heat loss through the combustion chamber walls. Thermal

49 barrier coatings have been extensively used in LHR engine designs, which increase the thermal

50 resistance of the combustion chamber walls and consequently increase the level of temperatures

51 inside the cylinder. From the first law of thermodynamics, it can be expected that any retained

52 energy by reducing heat losses through the chamber walls can be converted to useful work and

53 consequently improve the fuel conversion efficiency. The energy balance study on a partially

54 stabilized zirconia (PSZ) coated diesel engine by Modi et al. [6] reported that the heat loss to the

55 cooling system was decreased by $2 \%, 7 \%$, and $7 \%$ for low, medium, and high loads respectively

56 compared to the baseline engine. Praseth et al. [7] claimed 30-40\% reduction in coolant load was

57 achieved in coated engine, and a marginal improvement on the brake thermal efficiency was

58 observed. Srithar et al. [8] investigated the effects of thermal barrier coated combustion chamber

59 on a single cylinder diesel engine with dual biodiesel, the specific fuel consumption showed to 
60 be lower than that of the baseline engine by $13.9 \%$ and the reduction in coolant losses was found

61 to be around 5\%-25\%. Panneerselvam et al. [9] reported a review on the application of LHR

62 concept in bio-diesel engines, stating that the energy of bio-diesel can be released more

63 efficiently under LHR operation. Investigations by Kamo et al. [10] and Modi et al. [11] also

64 indicated promising improvements in fuel efficiency at high load conditions using multi-cylinder

65 diesel engines. Jafarmadar et al. [12] used a 3-D computational fluid dynamics code to further

66 study the combustion processes within the chamber of a LHR diesel engine from the perspective

67 of the second law of thermodynamics, which indicated that the exergy efficiency can be

68 improved by LHR concept at all the studied load conditions.

70 In addition, Reddy et al. [13] summarized that all of the simulation work proved the fuel 71 economy superiority of LHR engines over conventionally cooled engines. However, these facts

72 do not necessarily substantiate a conclusion that LHR engines will outperform the conventional

73 engine. In fact, some of the previous experimental work where the results are mixed show that a

74 number of engine operating parameters are inter-related which can negatively affect the

75 efficiency of a LHR engine. For instance, the higher operating temperature conditions decrease

76 the volumetric efficiency, which in turn adversely influences the energy conversion efficiency

77 [14]. Also, Caton [15-16] and Tunér [17] show that the resulting high gas temperatures in LHR

78 engines yield lower values of the specific heats ratio causing less effective conversion of energy

79 to work energy. Those conflicting results are mostly concluded from studies on ceramic-coated

80 engines; so far, relatively little attention has been devoted to investigating the possibility of LHR

81 engines with the approach of altering coolant temperature, which does not require significant

82 modifications on engine. Reductions in heat losses to the coolant jacket can be supposedly 
83 implemented by raising the engine coolant temperature (ECT), due to the smaller temperature

84 difference between the coolant and the wall. Only a few works, however, have reported the

85 benefits of operating engines at higher ECT conditions from the perspective of heat transfer [18-

86 19]. The main finding was that a higher ECT reduced the heat rejection to the coolant or the net

87 in-cylinder heat transfer rate, the associated gains also include enhancing fuel evaporation and

88 therefore mitigating hydrocarbon (HC) and $\mathrm{CO}$ emissions [20-21]. It seems therefore logical to

89 expand on the investigations of LHR concept through varying engine coolant temperature.

91 Typically, the operation conditions with ECT beyond $110^{\circ} \mathrm{C}$ are unlikely to be realized due to

92 the needs of avoiding excessive oil temperature [22]. The maximum ECT is also restricted by the

93 occurrence of nucleate boiling causing strong convection when the wall surface temperature goes

94 beyond the coolant saturation temperature. In this case, the simulation method allows for

95 extended studies at ECTs beyond the limited values on an actual engine. The current work is

96 aimed at providing a detailed consideration of the energy balance for a LHR engine using

97 elevated coolant temperatures. As described above, this is an area that has only received limited

98 attention in the past.

99

100 This paper describes a study that lays the foundation for simulation-based analysis of LHR 101 engines. The work complements a prior experimental study [23] of conventional and low102 temperature combustion with LHR and offers analytical tools to explore more deeply the 103 associated thermodynamics. The current study relies mostly on a one-dimensional engine 104 simulation using a pseudo-predictive combustion approach to predict the energy distributions for 105 a multi-cylinder light-duty diesel engine. This article begins with a brief introduction on the 
106 engine simulation model, which is followed by the theoretical work on the energy balance

107 methodology. Then, the results and discussion section presents the comparative study of energy

108 distributions between simulation and experiment, which is further applied to correlate the

109 improvements in fuel conversion efficiency to the changes in engine coolant temperature.

\section{2. Model Setup and Validation}

112 The diesel engine was modeled using a one-dimensional engine simulation software package

113 (GT-Power) [24]. Table 1 lists the main specifications of the engine. In general, such a system-

114 level engine model is developed with built-in templates providing detailed representation of the

115 engine components, such as intake and exhaust manifolds, cylinders, valve train, and engine

116 crank train.

118 The simulation model was validated using the steady-state measurements from the instrumented 119 engine where five operating conditions were tested [25]. Table 2 lists the settings of engine 120 speed, injection timing, fueling rate, and the primary independent parameter ECT. The engine is 121 maintained at a low load condition of $30 \mathrm{~N}-\mathrm{m}$, which is equivalent to approximately 2 bar brake 122 mean effective pressure (BMEP). The engine is operated at low ECTs and increased to $100^{\circ} \mathrm{C}$ to 123 provide trendwise behavior without exceeding safe operating temperatures. The experimental 124 measurements are collected from 200 consecutive cycles for each cylinder and ensemble 125 averaged.

127 With given inputs and defined boundary conditions, sub-models including heat transfer model, 128 combustion model, friction model, and nitrogen oxide $\left(\mathrm{NO}_{\mathrm{x}}\right)$ model were calibrated by 
129 reproducing the experimental data at the five test points. It should be noted that the engine

130 simulation does not include a submodel predicting blow-by fraction and crevice volume.

131

Table 1: Engine specifications

\begin{tabular}{ll}
\hline Engine type & DI Diesel Engine \\
Displaced volume & $1.9 \mathrm{~L}$ \\
Bore & $82 \mathrm{~mm}$ \\
Stroke & $90.4 \mathrm{~mm}$ \\
Connecting rod & $145.5 \mathrm{~mm}$ \\
Compression ratio (nominal) & $18: 1$ \\
Number of valves & 16 \\
Number of cylinders & 4 \\
Exhaust valve open & $112^{\circ}$ ATDC \\
Exhaust valve close & $356^{\circ}$ ATDC \\
Intake valve open & $361^{\circ}$ ATDC \\
Intake valve close & $-132^{\circ}$ ATDC \\
\hline
\end{tabular}

132

Table 2: LHR test matrix

\begin{tabular}{ccccc}
\hline Case \# & $\begin{array}{c}\text { Speed } \\
(\mathrm{RPM})\end{array}$ & $\begin{array}{c}\text { Injection timing } \\
\left({ }^{\circ} \mathrm{bTDC}\right)\end{array}$ & $\begin{array}{c}\text { Fueling rate } \\
(\mathrm{mg} / \mathrm{cycle})\end{array}$ & $\begin{array}{c}\mathrm{ECT} \\
\left({ }^{\circ} \mathrm{C}\right)\end{array}$ \\
1 & 1500 & 8 & 35.0 & 56.5 \\
2 & 1500 & 8 & 35.6 & 65 \\
3 & 1500 & 8 & 34.3 & 75 \\
4 & 1500 & 8 & 34.4 & 90 \\
5 & 1500 & 8 & 34.6 & 100 \\
\hline
\end{tabular}

134

135 The physics behind these submodels except for emission model were illustrated in details in the

136 previous work [26] and a systematic calibration procedure was developed to generate a single set

137 of model constants, which are capable of predicting the engine performance over multiple

138 operating points. The comparisons of cylinder pressures, flow characteristics, and most engine

139 performance parameters have also been validated in [26] showing that the predictions are

140 generally in agreement with the measurements, whereas disparities in the rates of heat release

141 (ROHR) are observed from the studied cases — one of which (\#4) is shown in Figure 1, the

142 validations for the remaining cases are listed in the Appendix A. These discrepancies, however,

143 do not cause a major concern since much of the use of the simulation is to capture 
144 thermodynamic parameters of the engine system where precise match in pressure is the first 145 priority.

147 Given that $\mathrm{NO}_{\mathrm{x}}$ emissions are closely associated with the combustion rate, the combustion model 148 needs to be calibrated with measurements prior to integrating the $\mathrm{NO}_{\mathrm{x}}$ model into the engine 149 simulation. The $\mathrm{NO}_{\mathrm{x}}$ model used for this simulation study is established based on the extended 150 Zeldovich mechanism, and the kinetic rate constants are taken from the recommended values 151 published in [27]. Figure 2 shows the comparison of $\mathrm{NO}_{\mathrm{x}}$ concentration (in units of ppm) and 152 brake specific $\mathrm{NO}_{\mathrm{x}}\left(\mathrm{BSNO}_{\mathrm{x}}\right)$ between the measurements and predictions. The error bars in all 153 data plots are created from different sets of measurements on two separate days. It should be 154 noted that the error bars for Case $\# 1\left(\mathrm{ECT}=56.5^{\circ} \mathrm{C}\right)$ are zero, since only one set of measurements 155 was attained. In general, the variations of simulation results have similar patterns to that 156 observed from the experimental data. The predicted $\mathrm{NO}_{\mathrm{x}}$ concentrations seem to be 157 overestimated by around 2-3\% compared to the measurements, but both results show an increase 158 with increasing ECT due to the retained energy causing higher in-cylinder temperatures [23].

159 The Zeldovich NO formation mechanism is sensitive to both pressure and temperature, but more 160 so temperature than pressure; as the simulated pressures match the validation data well, it is 161 likely that the simulation model's two-zone temperature calculation does not capture the 162 maximum temperature of the burned zone very accurately. Both the simulation and experiment 163 show gradual decreases in $\mathrm{BSNO}_{\mathrm{x}}$ due to the improvement in brake power exceeding the 164 increase of $\mathrm{NO}_{\mathrm{x}}$ emissions as ECT increases. The underprediction of $\mathrm{BSNO}_{\mathrm{x}}$ relative to 165 experimental BSNOx (compared to the overprediction of NOx concentration) results from an 166 underprediction in total mass flow rate through the simulated engine. It has been discussed in 
167 [26] that the predicted intake air mass for all the five cases showed to be relatively lower than 168 measurements by less than 5\%, where the errors are considered to be mainly caused by the 169 inaccuracy in the intake valve discharge coefficients.

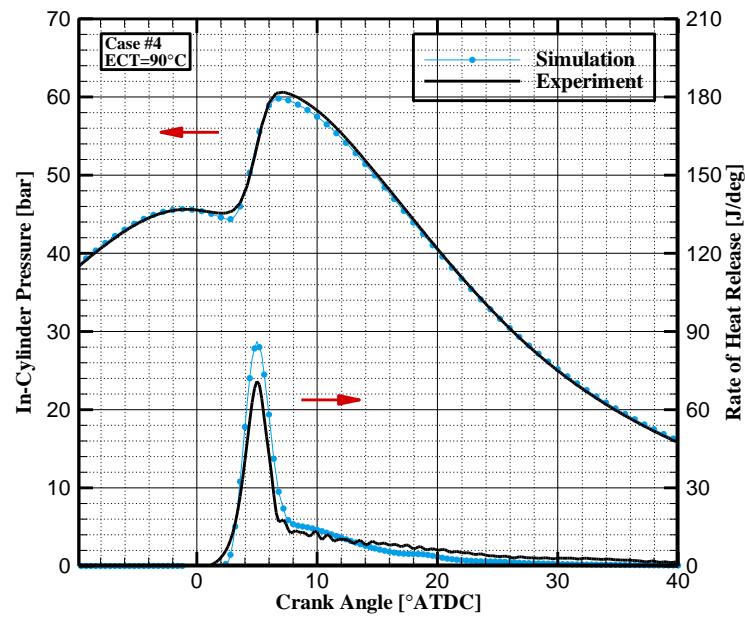

Figure 1 Validation of cylinder pressure and apparent heat release rate

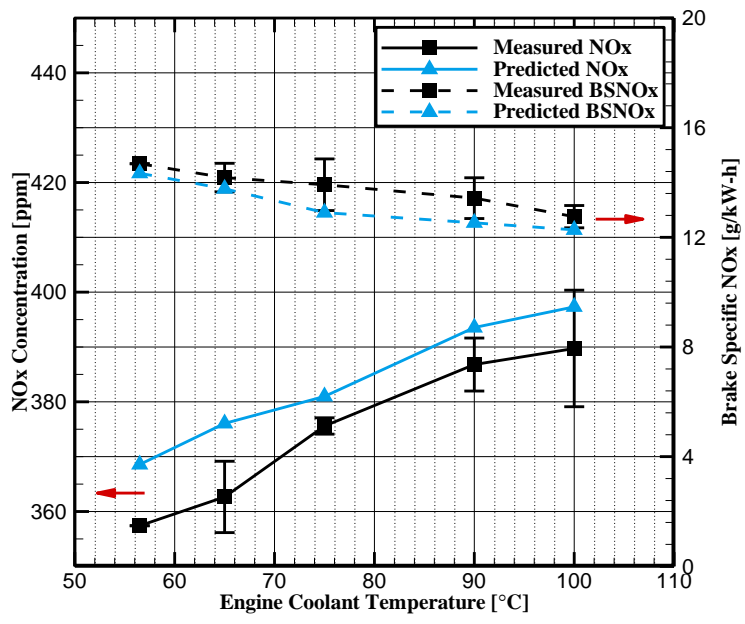

Figure 2 Comparison of $\mathrm{NO}_{\mathrm{x}}$ concentration and $\mathrm{BSNO}_{\mathrm{x}}$ between experiment and simulation

\section{3. Energy Path Analysis}

173 This study attempts to compare the energy distributions between the simulation and experiment,

174 the lack of information on turbocharger, intercooler and exact engine external structures (e.g., 175 engine block surfaces) prevents the simulation from capturing the unaccounted energy, i.e. the 176 heat rejected to the oil plus convection and radiation dissipated to the environment through the 177 engine's external surfaces. To ensure the experimental energy balance analyses follow a 178 consistent fashion of energy paths that the simulation can provide, a thermodynamic system by 179 taking the combustion chamber as the control volume (CV) was selected to develop the energy 180 balance analyses. Figure 3 depicts the energy flows of this system, and Eq. (1) is the overall 181 energy balance that provides information on the disposition of the input energy. For this control 
182 volume, blowby losses and crevice flows are neglected for both simulation and experimental 183 analyses.

184 185 186

188 The terms on the left represent input fuel energy and air energy, the energy flows leaving the walls (net in-cylinder heat transfer rate, $\left.\dot{Q}_{H T}\right)$, and exhaust energy $\left(\dot{m}_{\text {exh }} h_{\text {exh }}\right) . \dot{m}_{f}, \dot{m}_{\text {air }}$, and $191 \dot{m}_{\text {exh }}$ are corresponding to the mass flow rates of fuel, inducted air, and exhaust gas. $h_{f u e l}$ stands 192 for the enthalpy of fuel (\#2 diesel), which may be approximated with the lower heating value 193 since the sensible enthalpy is almost negligible as compared to the lower heating value. $h_{\text {air }}$ and $194 h_{\text {exh }}$ represent the enthalpies of air and exhaust gas, respectively. The engine simulation is 195 capable of providing complete information for these energy flows. The following subsections 196 will briefly review the methodologies used to experimentally determine these terms, i.e. net 197 indicated work, in-cylinder heat transfer, and exhaust energy. Table 3 gives the information 198 regarding how each term involved in Eq. (1) is quantified.

Figure 3 The engine combustion chamber as a thermodynamic open system operating in a

$$
\dot{m}_{f} h_{f u e l}+\dot{m}_{\text {air }} h_{\text {air }}=\dot{W}_{i, n e t}+\dot{Q}_{H T}+\dot{m}_{\text {exh }} h_{\text {exh }}
$$

control volume consist of net indicated power $\left(\dot{W}_{i, n e t}\right)$, heat transfer from gases to the chamber

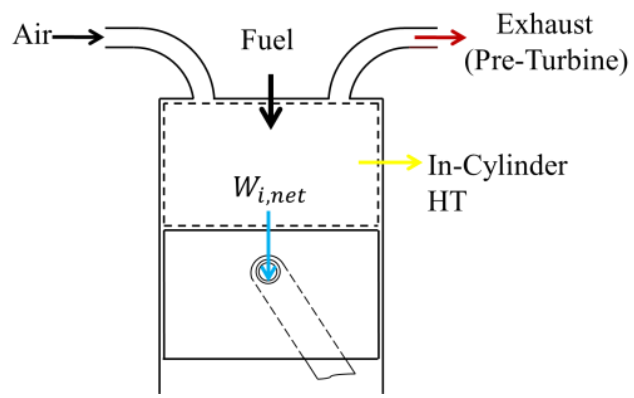


Table 3: Quantification of parameters for experimental energy balance analyses

\begin{tabular}{cl}
\hline Parameters & Quantification method \\
\hline$\dot{m}_{f}$ & Direct measurement \\
$\dot{m}_{\text {air }}$ & Direct measurement \\
$\dot{m}_{\text {exh }}$ & Direct measurement \\
$h_{\text {fuel }}$ & Approximated to be fuel LHV \\
$h_{\text {air }}$ & Derived from constitutive enthalpies using NASA Glenn polynomials \\
$h_{\text {exh }}$ & Derived from constitutive enthalpies using NASA Glenn polynomials \\
$\dot{W}_{i, n e t}$ & Calculated from experimental pressure-volume data, see Section 3.1 \\
$\dot{Q}_{H T}$ & Experimentally derived from available measurements, see Section 3.2 \\
\hline
\end{tabular}

202

\section{$203 \quad 3.1$ Net Indicated Work}

204 The net indicated work is the sum of the gross work and the pumping work, which are evaluated

205 from in-cylinder gas pressures by taking an integral over an engine's mechanical cycle:

$$
W_{i, n e t}=\oint p d V
$$

\subsection{In-Cylinder Heat Transfer}

208 Directly measuring in-cylinder heat transfer rate is usually complicated and typically requires

209 temperature measurements of multiple positions on the cylinder liner in order to obtain the

210 temperature field. An alternative way to obtain $\dot{Q}_{H T}$ is relating to the engine's overall heat

211 rejection to the environment (e.g., coolant system and other convective and radiative surface

212 losses) [28-29]. Namely, the in-cylinder heat transfer rate can be estimated by subtracting the

213 friction power $\left(\dot{W}_{f}\right)$ from the total heat rejection, which is the sum of coolant load $\left(\dot{Q}_{c o o l}\right)$ and

214 unaccounted energy $\left(\dot{Q}_{\text {unac }}\right)$.

$$
\dot{Q}_{H T}=\dot{Q}_{\text {cool }}+\dot{Q}_{\text {unac }}-\dot{W}_{f}
$$

215 The detailed derivation of Eq. (3) is developed in Appendix B. The heat rejection to the coolant

216 is determined from the temperature rise in the coolant $\left(T_{e}-T_{i}\right)$ as it passes through the engine 217 and the mass flow rate of coolant, $\dot{m}_{\text {cool }}$. 


$$
\dot{Q}_{\text {cool }}=\dot{m}_{\text {cool }} c_{p}\left(T_{e}-T_{i}\right)
$$

218 The dominant source of the unaccounted losses is the environmental heat losses [30], i.e. the heat

219 transfer from engine external surfaces to the surroundings by conduction, convection and

220 radiation. The calculations of the surface heat losses have been detailed in [25]. In contrast to the

221 other two energy flows that are directly derived from experimental measurements, using Eq. (3)

222 to calculate $\dot{Q}_{H T}$ may carry errors from the computations of the involved terms $\left(\dot{Q}_{\text {cool }}, \dot{Q}_{\text {unac }}\right.$,

223 and $\dot{W}_{f}$ ) in addition to errors from relevant measurements.

2253.3 Exhaust Energy

226 For steady state, the mass flow rate of the exhaust gas is known in terms of the measured mass

227 flow rates of air and fuel. Therefore, the energy carried by the exhaust gas can be determined 228 from the balance,

$$
\dot{m}_{\text {exh }} h_{\text {exh }}=\left(\dot{m}_{f}+\dot{m}_{\text {air }}\right) h_{\text {exh }}
$$

229 where the enthalpy of the exhaust gas is referenced to $298 \mathrm{~K}$. The exhaust gas is a known 230 mixture of numerous constitutive species, thus the exhaust enthalpy is namely the mixture 231 enthalpy determined from exhaust temperature and species concentrations. The heat of 232 combustion is aggregated into the exhaust enthalpy for species that have not been completely 233 oxidized, i.e. carbon monoxide (CO) and unburned $\mathrm{HC}$ emissions.

235 From the control volume shown in Figure 3, the target exhaust energy should be the energy 236 corresponding to a pre-turbine temperature, but only the post-turbine gas temperature was 237 attained from the experimental measurements. To better relate the experimentally derived 238 exhaust energy to that calculated by the simulation, it is necessary to analyze the temperature 
239 difference or the difference of energy carried by the exhaust gas between pre-turbine and post-

240 turbine. The difference in the energy between the two states consists of the work output from the

241 turbine and the heat transfer between the turbo surfaces and the environment. Due to the lack of

242 pre-turbine temperature and related gas velocity information, the turbine work cannot be directly

243 calculated from the changes in stagnation enthalpies between the states; solving the work

244 consumed by compressor $\left(W_{C}\right)$, however, is more straightforward with Eq. (6) and the following

245 assumptions:

246 - Negligible elevation difference;

247 - The surface heat losses across the compressor are usually small [30], which allows the 248 compressor to be approximated as an adiabatic control volume.

$$
\dot{W}_{C}=\dot{m}_{\text {air }}\left(h_{02}-h_{01}\right)
$$

249 Given that the minimum work transfer rate produced by turbine is namely $\dot{W}_{C}$ when the

250 mechanical efficiency of the turbocharger system is assumed to be $100 \%$, the work output from

251 the turbine can be consequently estimated from Eq. (6). Adding the total energy losses across the

252 turbine, i.e. the sum of turbine work and surface heat losses, onto the exhaust enthalpy calculated

253 from the post-turbine temperature yields the pre-turbine exhaust energy.

\section{4. Results and Discussion}

256 The methods described in the previous section are now applied to the experimental energy

257 balance analyses by using the control volume shown by Figure 3. These results are subject to the 258 constraints of the experimental measurements and to the approximations involved in the 259 methodology. First, this section compares the experimental results to the predictions from 260 simulation and attempts to explain the possible factors causing the disparities in the relevant 
261 energy terms. Then, the ultimate objective is using the energy balance to assess how the variation

262 in ECT impacts the energy conversion efficiency.

\section{4.1 Energy distributions}

265 Figure 4 compares the simulated energy fractions with the experimentally derived results for

266 Case $\# 4\left(\mathrm{ECT}=90^{\circ} \mathrm{C}\right)$. The comparisons for the remaining cases are displayed in the Appendix $\mathrm{C}$,

267 which appear to have similar pattern to that shown in Figure 4. The changes in the three different 268 energy flows with ECT are summarized in Figure 5.

270 In general, it is found from both simulation and experiment that more than $40 \%$ of the input fuel 271 energy is converted into net indicated power. The net indicated power slightly increases as the 272 ECT increases, more discussions on this will be detailed in section 4.2 along with discussions of 273 the fuel conversion efficiency. The simulation results are underestimated by approximately 2$2743 \%$, which do not deviate from the experimental results as much as the other two terms do. 275 Typically precise predictions in cylinder pressures can avoid significant inaccuracies of $W_{i, n e t}$, 276 because the net indicated work is usually derived from the pressure-volume analysis, see section

277 3.1. Since the simulated pressure is in good agreement with the validation data as indicated in 278 Figure 1, the uncertainties of the flow characteristics are suspected to be the primary reason 279 causing the errors in predicted net indicated power [26]. 


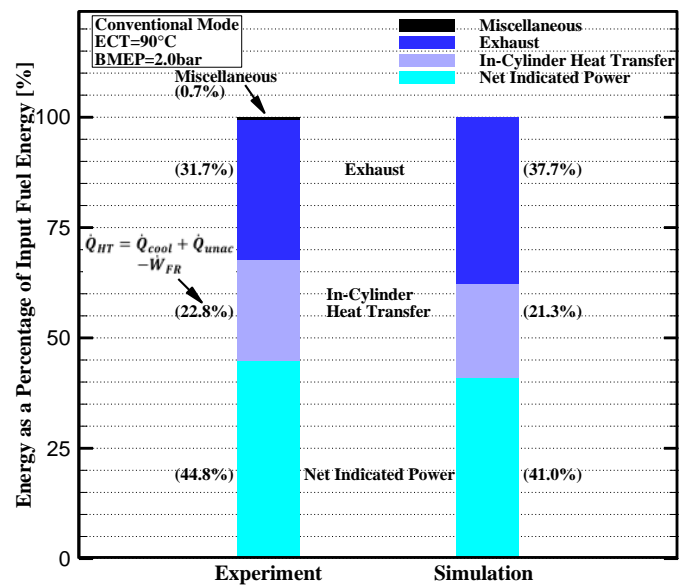

280

281

282 Similar to previous studies on LHR engines [10-11], raising ECT also yields gradually decreased

283 net in-cylinder heat transfer. Compared to the term of net indicated power, there are more

284 significant discrepancies in heat transfer existing between the simulation and experimentally

285 derived results. The in-cylinder heat transfer fractions determined from Eq. (3) reveal to be

286 higher than the simulation by about 2-6\%. As discussed in section 3.2, using Eq. (3) to estimate

287 the in-cylinder heat transfer will likely result in substantial inaccuracies since the process tends

288 to introduce additional errors from calculating $\dot{Q}_{c o o l}$ and $\dot{Q}_{\text {unac }}$. For example, the $\dot{Q}_{c o o l}$ is

289 calculated based on the assumption of constant coolant properties, i.e. constant pressure specific

290 heat. In addition, the friction power is obtained by subtracting brake power from net indicated

291 power rather than directly measuring from motoring engine. In this work, a more significant

292 source of errors is likely to be the computation of $\dot{Q}_{u n a c}$. It is usually difficult to accurately

293 capture the heat losses to the environment, especially when operating the engine under LHR 294 conditions where higher engine surface temperature yields more radiative heat transfer occurring 
295 between external surfaces and the environment; also, the heat transfer coefficients used for the

296 calculations are collected from empirical correlations. Since a direct measurement of heat flux is

297 not available in this study, an alternative way to further examine the simulation results is

298 calculating the cylinder heat transfer from measured pressures by using Hohenberg's correlation

299 [31]. The comparison between engine simulation and Hohenberg model results are detailed in the

300 Appendix D.

301

302 On the contrary, experimental exhaust energy fractions tend to be lower than the simulation 303 results by $6-7 \%$, which nearly offsets the disparity found in the heat transfer term. The 304 methodology used to calculate experimental exhaust energy has been introduced in section 3.3.

305 The primary source of errors in the exhaust energy estimation is suspected to be the location of 306 exhaust temperature measurement. Based on the energy systems depicted in Figures 3, the actual 307 exhaust energy should be calculated from the pre-turbine exhaust temperature; more specifically, 308 the target temperature should be measured at a position near the exhaust valve or the upstream 309 end of exhaust manifold, i.e. state 1 shown in Figure 6. As discussed in section 3.3, the post310 turbine temperature (temperature at state 3, see Figure 6) is the only available measurement from 311 the instrumented engine. Although the experimental data has been corrected to be the pre-turbine 312 exhaust energy (state 2), the experimentally calculated exhaust energy is still not an exactly 313 "parallel" reference to the simulation-based counterpart; the latter is, therefore, higher than the 314 former due to the lower exhaust gas temperature used for the experimental analyses. As 315 mentioned earlier, such a constraint in temperature measurement consequently causes the heat 316 transfer occurring between exhaust gases and exhaust port walls to be counted toward the in- 
317 cylinder heat transfer in the experimental calculations, which yields a corresponding difference

318 from the simulated heat transfer.

323 A sensitivity study was completed to evaluate how much the exhaust temperature affects the

324 level of exhaust energy. Figure 7 gives the exhaust energy fractions at different exhaust

325 temperatures, where the baseline measurement refers to the result computed from the post-

326 turbine exhaust temperature and the maximum temperature $500 \mathrm{~K}$ is set to be the simulated

327 temperature at the target position, i.e. state 1. Changing the exhaust temperature, from post-

328 turbine temperature $418 \mathrm{~K}$ to $500 \mathrm{~K}$, yields different exhaust energy fractions being denoted by

329 the bars in Figure 7, which tend to increase linearly with the temperature. Square symbols

330 represent the relative changes in exhaust energy with respect to the baseline case, which appear

331 to be about 2.5 times faster than the rate of relative change in exhaust temperature, as denoted by

332 the triangle symbols. In general, the exhaust energy is shown to be very sensitive to the

333 temperature; for Case \#4, the exhaust energy fraction rises by $48.1 \%$ (from $25.1 \%$ to $37.2 \%$ ) as

334 the exhaust temperature relatively increases by $19.6 \%$ (from $418 \mathrm{~K}$ to $500 \mathrm{~K}$ ). Such analysis 
confirms the need to have proper exhaust temperature measurement when calculating the exhaust enthalpy. Apart from the uncertainties involved in experimental analyses, there are also some

337 potential inaccuracies existing in the simulation work. For example, generally the combustion 338 models provided by the engine simulation software do not have the capability to predict the 339 hydrocarbon emissions for compression ignition engine models. This means that the simulated 340 exhaust energy does not account for the portion carried by the unburned hydrocarbons.

341

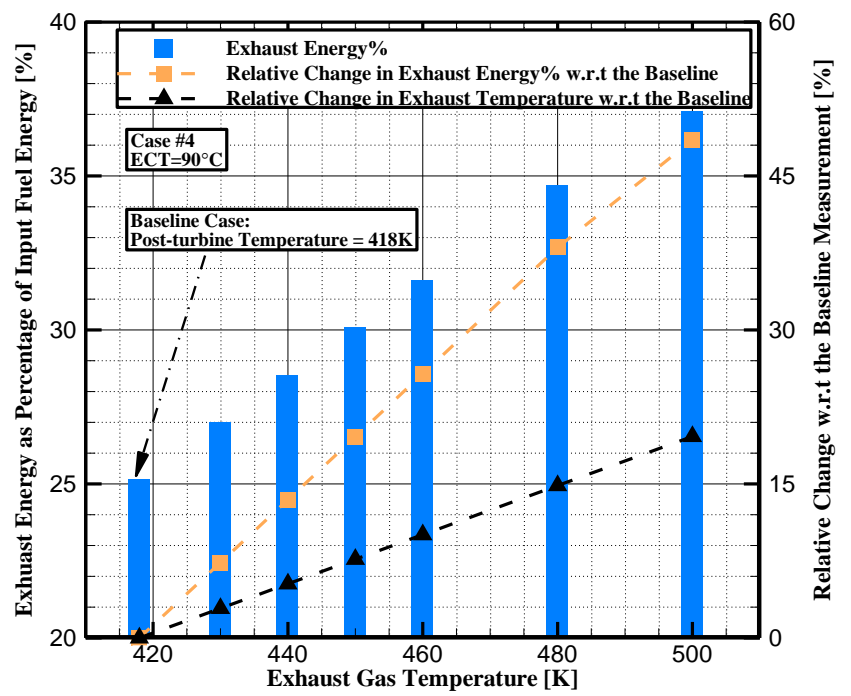

Figure 7 Sensitivity study on exhaust temperature for ECT $=90^{\circ} \mathrm{C}(\mathrm{Case} \# 4)$

\subsection{Fuel conversion efficiency}

Significant improvements in brake fuel conversion efficiency were observed in both simulation and experimental studies, as it is suggested in Figure 8. The simulation results indicate that over $20 \%$ relative improvement in the brake fuel conversion efficiency (from $21.1 \%$ to $26.4 \%$ ) is achieved as ECT changes from $56.5^{\circ} \mathrm{C}$ to $100^{\circ} \mathrm{C}$; the experimental analyses also indicate a similar level of improvement $(\sim 23.5 \%)$. The net indicated fuel conversion efficiency, however, reveals only slight improvement compared to that shown by brake efficiency. Increasing ECT 
351 from $56.5^{\circ} \mathrm{C}$ to $100{ }^{\circ} \mathrm{C}$ causes only $2.7 \%$ relative improvement in the experimental net indicated 352 efficiency, such insignificant efficiency gains are also found in the simulation study.

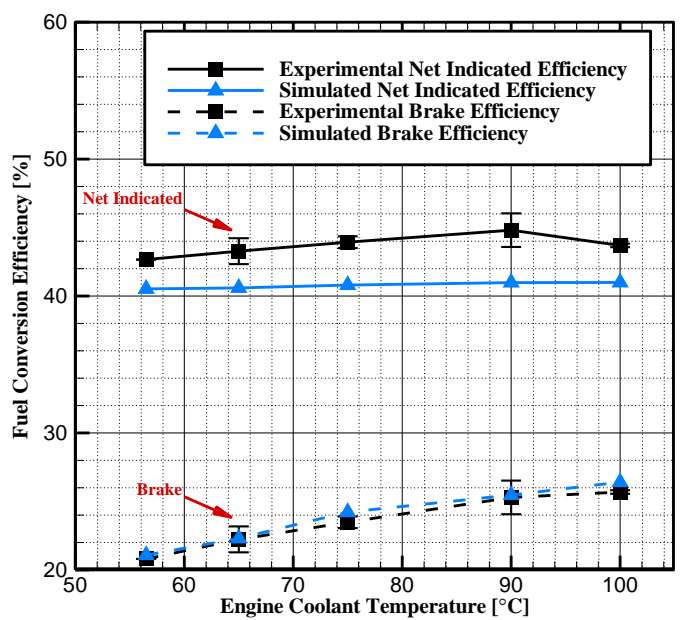

Figure 8 Fuel conversion efficiencies as functions of ECT

In general, the LHR application improves the fuel conversion efficiencies, which may be attributed to several beneficial phenomena caused by elevated ECT:

- Reduced in-cylinder heat transfer resulting in higher gas temperatures promotes the combustion toward completeness. It has been reported in [23] that increasing ECT reduces $\mathrm{CO}$ and $\mathrm{HC}$ pollutants, they serve as indicators of an increase in combustion efficiency. Such efficiency gains would be observed in both brake and indicated fuel conversion efficiencies; this may partly explain the slight increase in experimental indicated efficiency, which would not appear in the simulation indicated efficiency as the simulation does not capture $\mathrm{CO}$ and $\mathrm{HC}$.

- Retained energy from the LHR operation yields shorter ignition delay (ID), which might result in an increased effective expansion ratio depending on the influence of ignition delay on combustion duration. Figure 9 shows how the ignition delay, defined as the interval between start of injection (SOI) and 10\% mass fraction burned (MFB), and 
combustion duration (10-90\% MFB) change with the engine coolant temperature, the ignition delay gradually decreases as ECT increases. It is known that the injection timing for the studied cases is constant at $8^{\circ} \mathrm{bTDC}$, the high-temperature condition facilitates the start of combustion to be advanced and consequently the ignition delay tends to become shorter at higher ECTs. A subsequent extension of the combustion duration is due to the shorter ignition delay causing the fraction of burned gases in the premixed combustion phase to reduce, and the fraction of diffusion combustion consequently increases. Generally, diffusion combustion burns at a slower rate such that, for a fixed amount of fuel, increased diffusion burning at the expense of premixed burning will increase combustion duration. The predicted combustion durations deviate from validation data significantly, which likely results from the overestimated burn rates from the engine simulation. Figure 10 compares the experimental burn rates with that calculated by the engine simulation having prescribed pressure history, which indicates that the engine simulation cannot achieve perfect MFB matching even with measured pressures as the input. This is likely because the simulation code is using different methodologies or assumptions to calculate the burn rate. Whereas the simulation results do characterize a variation pattern consistent with the experiment, providing clues to help explain the gains in engine efficiency. In summary, changes to combustion phasing will impact both indicated and brake efficiencies; even though combustion phasing may change slightly at various ECTs, the changes do not appear to be substantial enough to cause significant changes to indicated efficiency. 


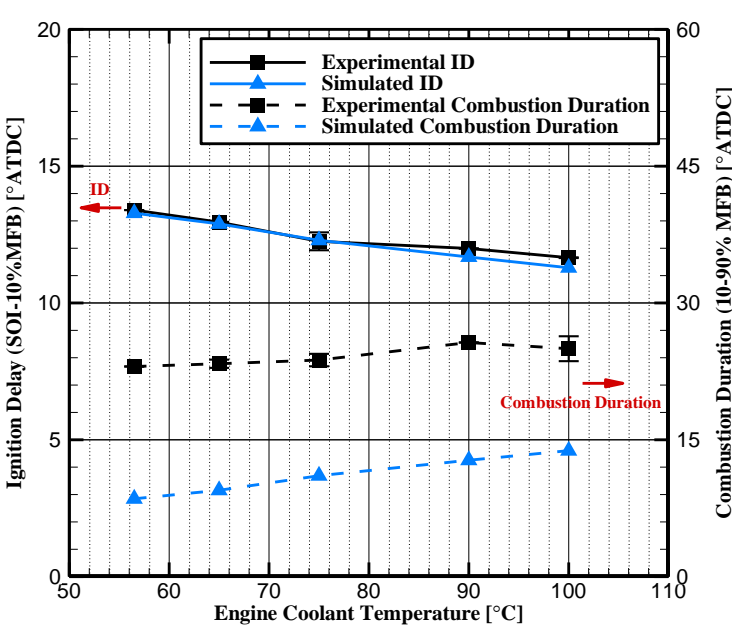

Figure 9 Ignition delay and combustion duration as functions of ECT

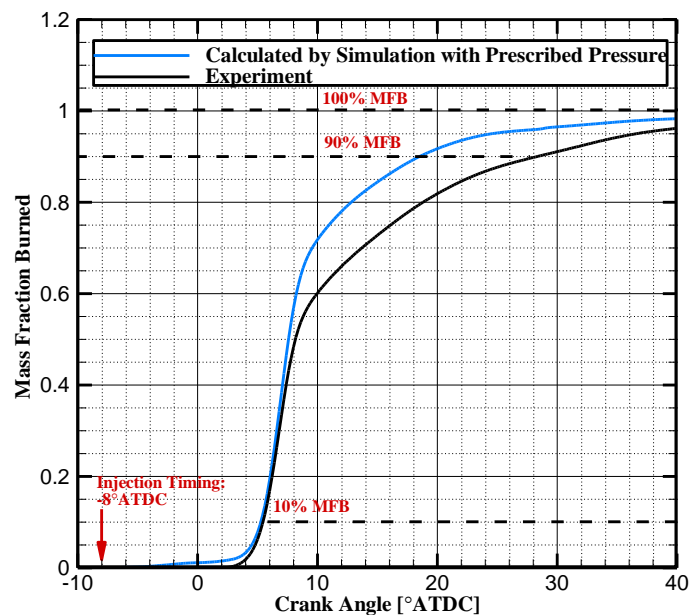

Figure 10 Comparison of burn rates (mass fraction burned), Case \#1

- Frictional losses decrease at higher temperature conditions. For the conventional low load condition, the reduction in friction is likely to be the dominant factor causing the noticeable improvement in brake efficiency. Robinson [22] also points out that increasing the coolant temperature of a conventional cooling system usually yields a fuel consumption benefit via reduced crank train friction. This is perhaps due to lowered lubricant viscosity as wall and oil temperatures increase with higher ECTs, decreasing the hydrodynamic friction in bearings, valve trains, along liners, and in the oil pump. Figure 11 indicates the decrease in friction mean effective pressure (FMEP) and increase in mechanical efficiency at higher ECTs, respectively. 


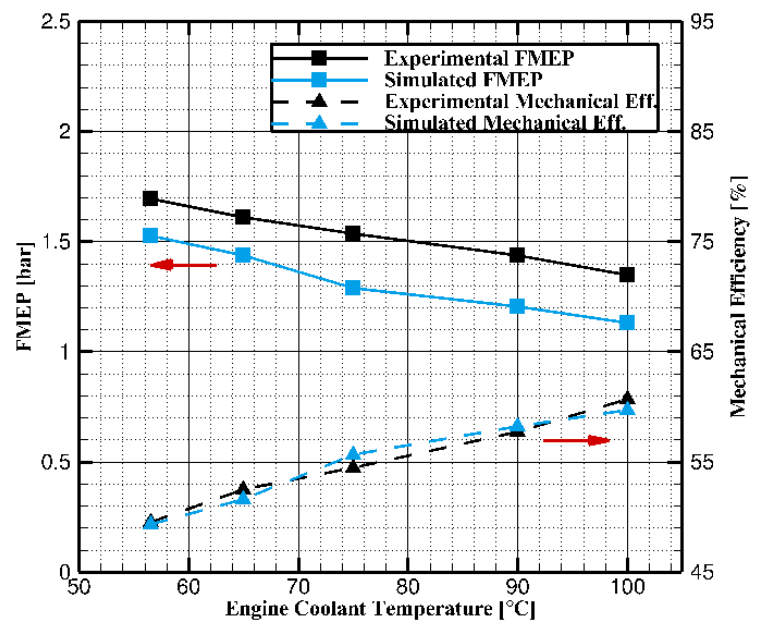

Figure 11 FMEP and mechanical efficiency as functions of ECT

\section{Summary and Conclusions}

406 The first law of thermodynamics was implemented to examine the strategy of altering engine 407 coolant temperature to devise a version of LHR application in a conventional light-duty diesel 408 engine. With the combustion chamber based control volume, a comparative study between 409 simulation and experiment was carried out to investigate the disposition of initial input energy at 410 five different ECTs. Due to the constraints involved in the measurements, the methodology used 411 for the experimental energy balance analyses was also carefully scrutinized to better analyze the 412 simulation results.

\section{$413 \quad 5.1$ Research findings}

414 - Both the experimental and simulation results indicate that more than $40 \%$ of the input 415 fuel energy is converted to net indicated work, about $1 / 3$ of the energy is rejected to the 416 exhaust gases and the rest is transferred as thermal energy through the combustion 417 chamber walls. Regarding to the net indicated power as a percentage of the total fuel 418 energy, simulation results are generally in agreement with the validation data. Noticeable 
disparities were found in exhaust energy fractions due to the constraint of the exhaust temperature measurement, which also partly causes the likely overestimation of experimental in-cylinder heat transfer. Potential uncertainties involved in the engine simulation are also discussed to explain the observed disparities.

- To better understand the proposed LHR concept, the energy balance results are further applied to correlating the fuel conversion efficiency to the variations in ECT. It is found that increasing ECT yields reduction in cylinder heat transfer but almost equivalent

- The second phase of this study is to investigate the gains in engine performance and emissions mitigation through the integration of the proposed LHR concept with low temperature combustion strategy.

- The possible limits of the proposed LHR technique can also be explored through achieving more aggressive reduction in the heat rejection, extended studies at wider operation range, such as high load and high speed conditions, will help to better 


\section{Acknowledgements}

443 This work was supported by National Science Foundation under grant \# 1343255 and General

444 Motors Research \& Development. Additionally, the authors wish to acknowledge Dr. Stephen

445 Busch and Dr. Kan Zha, researchers at Sandia National Laboratories, for their assistance in

446 providing the injection rate data. Any opinions or views expressed in this manuscript are not

447 necessarily those of the sponsoring agency.

\section{References}

[1] Caton JA. Thermodynamic considerations for advanced, high efficiency IC engines. J Eng Gas Turbines Power 2013;136. doi: $10.1115 / 1.4027295$.

[2] Abedin MJ, Masjuki HH, Kalam MA, Sanjid A, Ashraful AM. Combustion, performance, and emission characteristics of low heat rejection engine operating on various biodiesels and vegetable oils. Energy Conversion and Management 2014; 85 . doi: 10.1016/j.enconman.2014.05.065.

[3] Kamo R, Bryzik W. Ceramics for adiabatic turbocompound engine. In: Lenoe EM, Katz RN, Burke JJ, editor. Ceramics for high-performance applications III. New York: Plenum Press; 1979.

[4] Wade WR, Trinker FH. Fuel economy opportunities with an uncooled di diesel engine. SAE paper no. 841286; 1984. doi: 10.4271/841286.

[5] Thring RH. Low heat rejection engines. SAE paper no. 860314; 1986. doi: 10.4271/860314.

[6] Modi A. Experimental study of energy balance in thermal barrier coated diesel engine. SAE paper 2012-01-0389; 2012. doi: 10.4271/2012-01-0389.

[7] Prarath BR, Tamilporai P, Shabir MF. Analysis of combustion, performance and emission characteristics of low heat rejection engine using biodiesel. International Journal of Thermal Sciences. 2010;49:2483-2490. doi:10.1016/j.ijthermalsci.2010.07.010.

[8] Srithar K, Balasubramanian KA, Vivar M, Skryabin I. An experimental investigation on diesel and low heat rejection engines with dual biodiesel blends. International Journal of Green Energy 2013; 10. doi: 10.1080/15435075.2012.738448.

[9] Panneerselvama N, Murugesanb A, Vijayakumarb C, Kumaravelc A, Subramaniamc D, Avinashd A. Effects of injection timing on bio-diesel fuelled engine characteristics-An overview. Renewable and Sustainable Energy Reviews 2015; 50. doi: 10.1016/j.rser.2015.04.157.

[10] Kamo R, Mavinahally N, Kamo L, Bryzik W. Injection characteristics that improve performance of ceramic coated diesel engines. SAE paper no. 1999-01-0972; 1999. doi: 10.4271/1999-01-0972.

[11] Modi A, Gosai D. Experimental study on thermal barrier coated diesel engine performance with blends of diesel and palm biodiesel. SAE paper no. 2010-01-1519; 2010. doi: 10.4271/2010-01-1519. 
[12] Jafarmadar S, Tasoujiazar R, Jalilpour B. Exergy analysis in a low heat rejection IDI diesel engine by three dimensional modeling. International Journal of Energy Research 2014; 38. doi:10.1002/er.3100. [13] Reddy C, Domingo N, Graves R. Low heat rejection engine research status: where do we go from here? SAE paper no. 900620; 1990. doi: 10.4271/900620.

[14] Giakoumis EG. Cylinder wall insulation effects on the first- and second-law balances of a turbocharged diesel engine operating under transient load conditions. Energy Conversion and Management. 2007;48:2925-2933. doi:10.1016/j.enconman.2007.07.013.

[15] Caton JA. Thermodynamic advantages of low temperature combustion (LTC) engines using low heat rejection (LHR) concepts. SAE paper no. 2011-01-0312; 2011. doi: 10.4271/2011-01$\underline{0312 .}$.

[16] Caton JA. On the importance of specific heats as regards efficiency increases for highly dilute IC engines. Energy Conversion and Management 2014; 79. doi:10.1016/j.enconman.2013.12.020.

[17] Tunér M. Studying the potential efficiency of low heat rejection HCCI engines with a stochastic reactor model. SAE paper no. 2009-24-0032; 2009. doi: 10.4271/2009-24-0032.

[18] Torregrosa AJ, Olmeda P, Marti'n J, Degraeuwe B. Experiments on the influence of inlet charge and coolant temperature on performance and emissions of a DI diesel engine. Experimental Thermal and Fluid Science 2006;30. doi:10.1016/j.expthermflusci.2006.01.002.

[19] Burke R, Brace C. The effects of engine thermal conditions on performance, emissions and fuel consumption. SAE paper no. 2010-01-0802; 2010. doi: 10.4271/2010-01-0802.

[20] Kim H, Shon J, Lee K. A Study of fuel economy and exhaust emission according to engine coolant and oil temperature. Journal of Thermal Science and Technology 2013; 8. doi: 10.1299/jtst.8.255.

[21] Kim S, Yan Y, Nouri JM, Arcoumanis C. Effects of intake flow and coolant temperature on the spatial fuel distribution in a direct-injection gasoline engine by PLIF technique. Fuel 2013; 106. doi: $10.1016 /$ j.fuel.2012.10.002.

[22] Robinson K. IC engine coolant heat transfer studies ( $\mathrm{PhD}$ thesis). Bath, UK: University of Bath; 2001.

[23] Penny MA, Jacobs TJ. Efficiency improvements with low heat rejection concepts applied to diesel low temperature combustion. International Journal of Engine Research. 2015:1-15. doi: $10.1177 / 1468087415597628$.

[24] Gamma Technologies. GT-SUITE engine performance application manual (Version 7.5). 2015.

[25] Penny MA. Efficiency improvements with low heat rejection concepts applied to low temperature combustion (MS thesis). Texas A\&M University: Texas A\&M University; 2014. [26] Li T, Caton JA, Jacobs TJ. Use of an engine simulation to study low heat rejection (LHR) concepts in a multi-cylinder light-duty diesel engine. SAE paper no. 2016-01-0668; 2016. doi: 10.4271/2016-01-0668.

[27] Bowman CT. Kinetics of pollutant formation and destruction in combustion. Progress in Energy and Combustion Science. 1975;1:33-45. doi:10.1016/0360-1285(75)90005-2.

[28] Alkidas AC. The use of availability and energy balances in diesel engines. SAE paper no. 890822; 1989. doi: $10.4271 / 890822$.

[29] Moore CH, Hoehne JL. Combustion chamber insulation effect on the performance of a low heat rejection Cummins V-903 engine. SAE paper no. 860317; 1986. doi: $10.4271 / 860317$. 
526 [30] Heywood JB. Internal combustion engine fundamentals: McGraw-Hill; 1988.[31] 527 Hohenberg G. Advanced approaches for heat transfer calculations. SAE paper no. 790825; 1979. 528 doi: $10.4271 / 790825$.

529 [31] Hohenberg G. Advanced approaches for heat transfer calculations. SAE paper no. 790825; 530 1979. doi: $10.4271 / 790825$.

531 [32] Taymaz I. An experimental study of energy balance in low heat rejection engine. Energy. 532 2006;31:364-71. doi:10.1016/j.energy.2005.02.004.

533 [33] Wallace SJ, Kremer KG. Diesel engine energy balance study operating on diesel and 534 biodiesel fuels. In: Proceedings of 2008 ASME International Mechanical Engineering Congress 535 and Exposition. Boston, Massachusetts; 2008. doi:10.1115/IMECE2008-67712.

536 [34] Modi AJ. Experimental study of energy balance in thermal barrier coated diesel engine. 537 SAE paper no. 2012-01-0389; 2012. doi: 10.4271/2012-01-0389. 


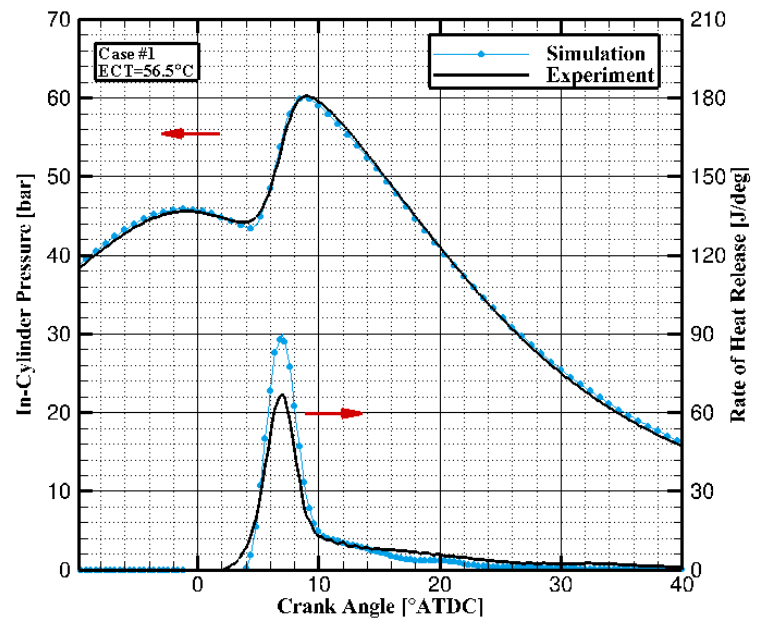

Figure 12 Validation of pressure and ROHR

(Case\#1)

574

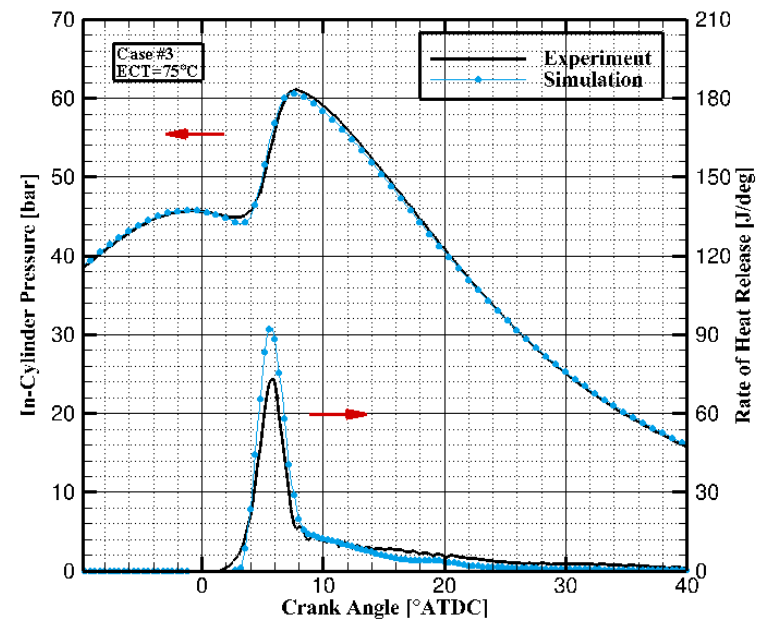

Figure 14 Validation of pressure and ROHR

(Case\#3)

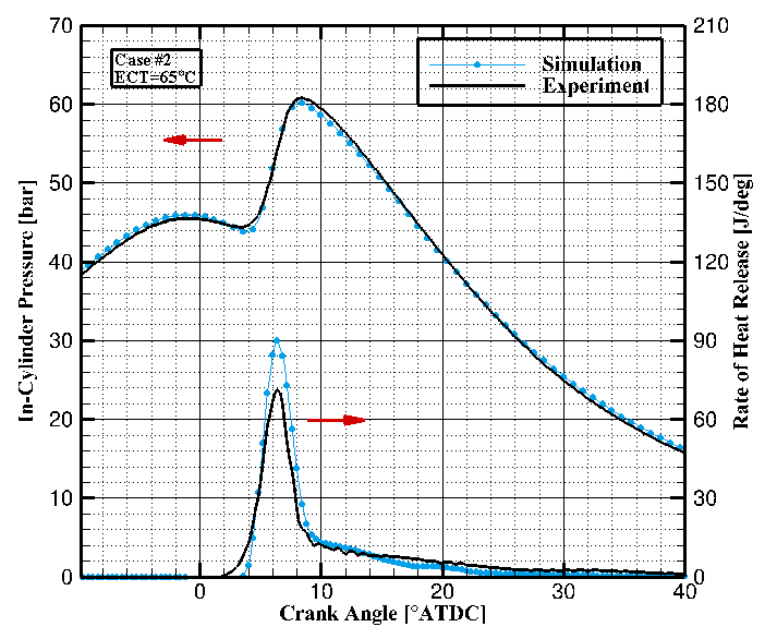

Figure 13 Validation of pressure and ROHR

(Case\#2)

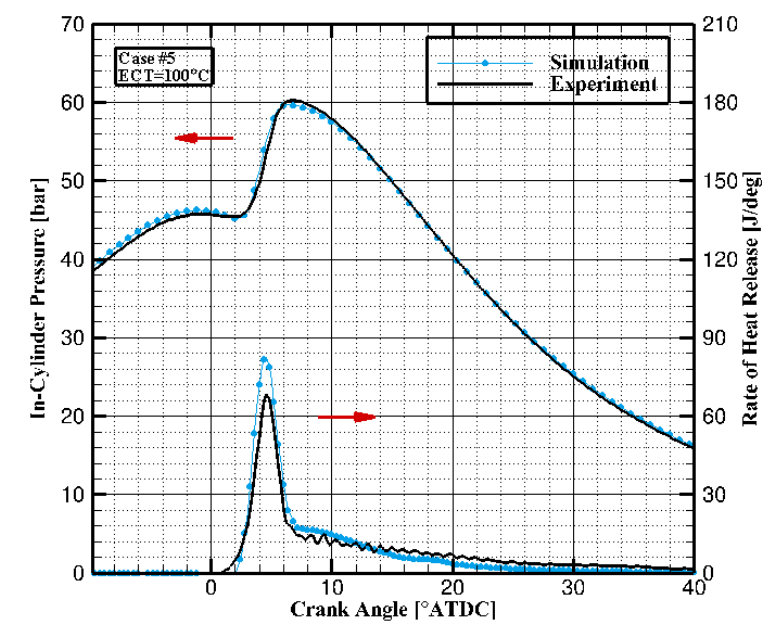

Figure 15 Validation of pressure and ROHR

(Case\#4) 


\section{Appendix B}

581 In some previous studies on engine energy balance, the engine block has been considered as the

582 steady-state control volume with air and fuel energy entering the open system and four energy

583 flows leaving the system [32-34]. As can be seen from Figure 16, these four energy flows

584 leaving the control volume are brake power $\left(\dot{W}_{b}\right)$, heat losses to the coolant $\left(\dot{Q}_{c o o l}\right)$, exhaust

585 energy $\left(\dot{m}_{\text {exh }} h_{\text {exh }}\right)$, and the unaccounted energy $\left(\dot{Q}_{\text {unac }}\right)$.

$$
\dot{m}_{f} h_{f u e l}+\dot{m}_{\text {air }} h_{\text {air }}=\dot{W}_{b}+\dot{Q}_{c o o l}+\dot{m}_{\text {exh }} h_{\text {exh }}+\dot{Q}_{u n a c}
$$

586 It is evident that the major difference between Eq. (7) and Eq. (1) is the energy flows leaving the

587 control volume. The unaccounted energy includes the heat rejected to the oil plus convection and 588 radiation dissipated to the environment through the engine's external surfaces.

592 In addition to what shown in Eq. (2), the net indicated work can also be expressed as a 593 relationship of different forms of work:

$$
W_{i, n e t}=W_{b}+W_{f}
$$

594 All the work terms discussed in this paper are referred to as the absolute values without 595 accounting for the sign convention, and the relationship of Eq. (8) can also be applied to the 596 corresponding power parameters. Comparing to the different control volume system described in 
597 Figure 3, rearranging Eqs. (1), (7), and (8) yields the net in-cylinder heat transfer rate $\dot{Q}_{H T}$ as 598 given by Eq. (3).

599

600

601

602

603

604

605

606

607

608

609

610

611

612

613

614

615

616

617

618

619 


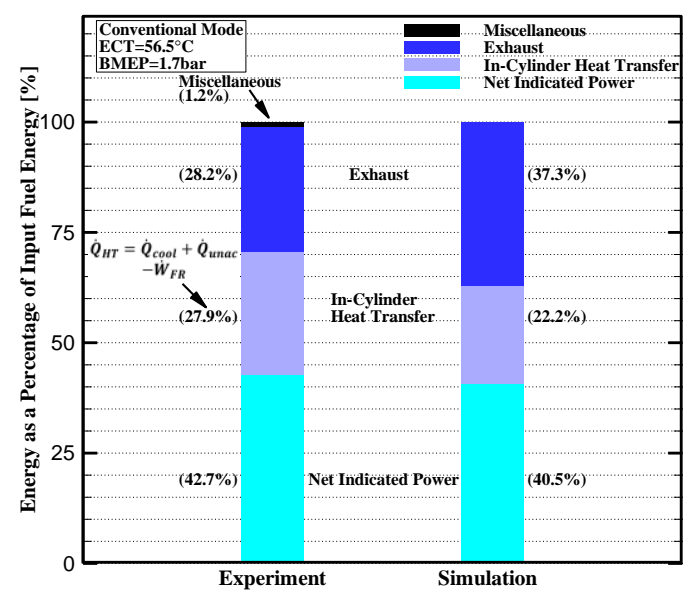

621

Figure 17 Energy distributions of experiment and simulation for Case \#1

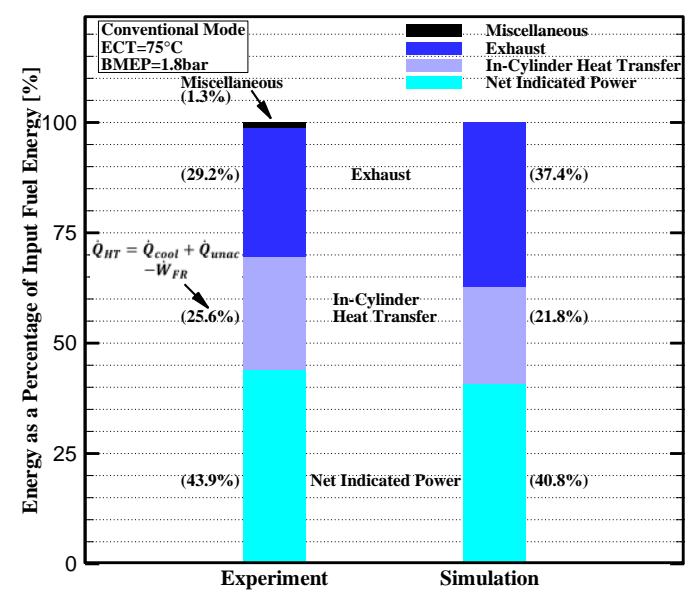

622

623

624

625

626

627

628
Figure 19 Energy distributions of experiment and simulation for Case \#3

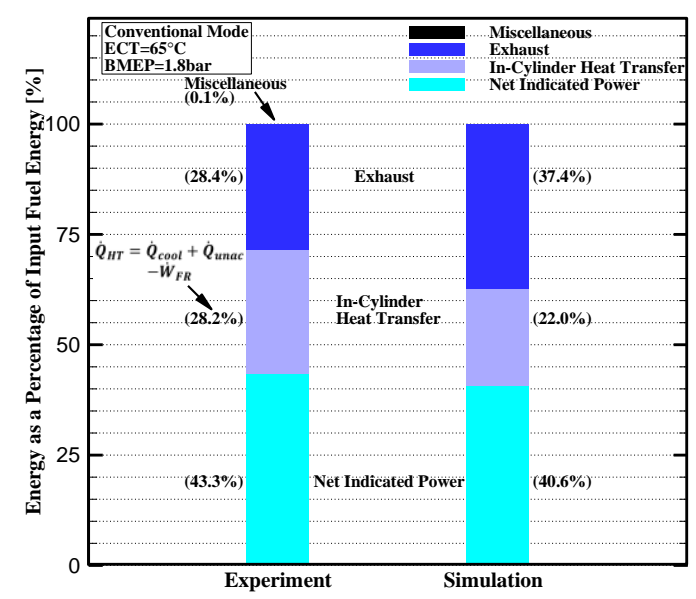

Figure 18 Energy distributions of experiment and simulation for Case \#2

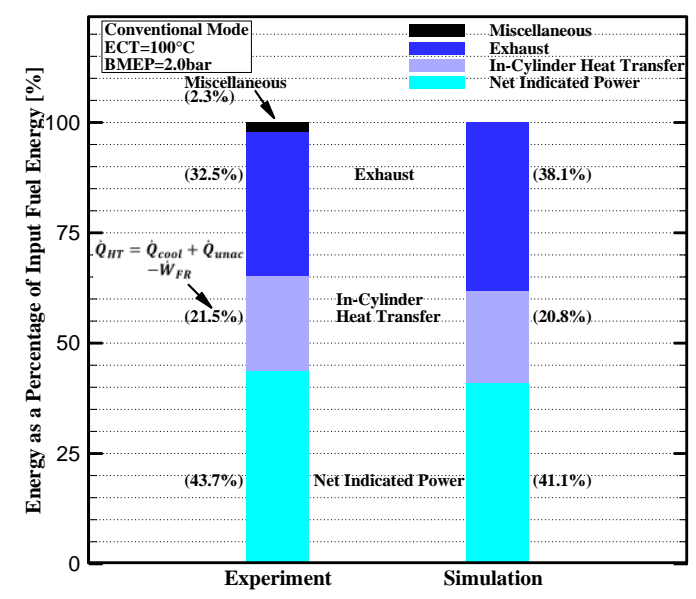

Figure 20 Energy distributions of experiment and simulation for Case \#5 


\section{Appendix D}

630 Figure 21 compares the instantaneous heat transfer rates calculated from Hohenberg's model and

631 the simulated rates predicted from WoschniGT model, i.e. the simulation data reported in Figure

632 4. The estimations from Hohenberg's correlation show to be higher than the WoschniGT

633 simulation results during the compression stroke, but which are significantly lower as

634 combustion starts. The average heat flux calculated from Hohenberg's correlation is lower than

635 the WoschniGT simulation results by about 3-5\%, see Figure 22. These comparisons are

636 consistent with studies of the heat transfer modeling between Hohenberg's model and the classic

637 Woschni's model [31]. Typically, most models do not account for heat transfer between the hot

638 gases and valve back. The heat transferred from gas through the intake/exhaust port walls is also

639 excluded from both modeling results, which is unavoidably lumped into experimental analyses

640 due to the constraint in exhaust temperature measurements. Therefore, the experimentally

641 derived in-cylinder heat transfer is likely to be overestimated compared to the simulation results.

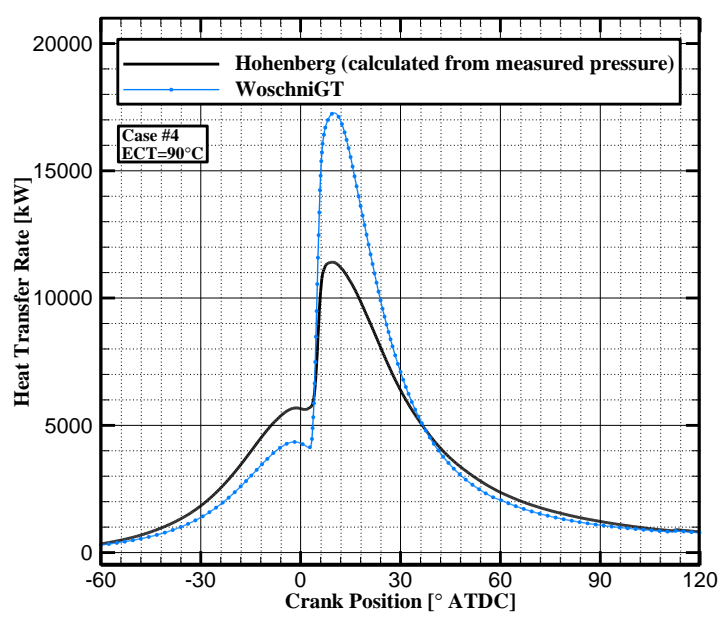

Figure 21 Heat transfer rates predicted from

Hohenberg and WoschniGT models

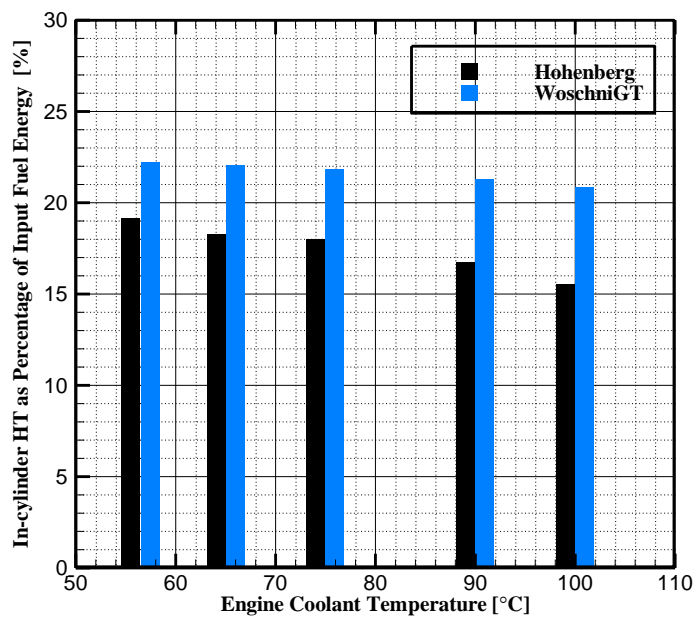

Figure 22 Average heat transfer predicted from

Hohenberg and WoschniGT models 